\title{
Knockdown of pleiotrophin increases the risk of preeclampsia following vitrified-thawed embryo transfer
}

\author{
SHENGXIAN LIU, FANG WANG and GELIN LIU \\ Reproductive Medicine Center, Luoyang Central Hospital \\ Affiliated to Zhengzhou University, Luoyang, Henan 471000, P.R. China
}

Received December 27, 2017; Accepted May 2, 2018

DOI: 10.3892/ijo.2018.4540

\begin{abstract}
Preeclampsia (PE) in pregnancy is associated with vitrified-thawed embryo transfer. Pleiotrophin (PTN) is important in inflammation via its receptors. The aim of the present study was to determine the effect of PTN on the risk of PE following embryo transfer. An enzyme-linked immunosorbent assay was performed to determine the levels of tumor necrosis factor (TNF)- $\alpha$ and PTN in serum. The knockdown of PTN was conditionally induced by tamoxifen (tax) treatment. The tail-cuff method and Bradford assay were used to monitor blood pressure and the level of urine protein, respectively. The expression patterns of PTN, receptor protein tyrosine phosphatase $\beta / \zeta$, (RPTP $\beta / \zeta)$, syndecan-1 (SDC1), syndecan-3 (SDC3) and anaplastic lymphoma kinase (ALK) were determined by immunohistochemistry (IHC). Western blot analysis was performed to evaluate the expression level of PTN and its receptors. The risk of PE was elevated following embryo transfer in clinical and in the $\operatorname{tax} / \mathrm{PTN}^{-/-}$group. It was found that the level of PTN increased when pregnancy progressed in normal conditions, however, the level of PTN was reduced in the PE mice. In addition, increases in TNF- $\alpha$, blood pressure and urine protein were more marked in the PE mice that lacked PTN, compared with those in other PE mice. In addition, overlapping expression of PTN and its receptors in villous mesenchyme and fetal macrophages were identified using an IHC assay. However, the positive staining of PTN and its receptors was weaker or even absent in the PE mice. The protein level of RPTP $\beta / \zeta$ was lower in the PE mice that lacked PTN than that in the other PE mice. The knockdown of PTN increased the risk of PE following vitrified-thawed embryo transfer, in which its receptors, particularly $\mathrm{RPTP} \beta / \zeta$, may be involved.
\end{abstract}

Correspondence to: Dr Shengxian Liu, Reproductive Medicine Center, Luoyang Central Hospital Affiliated to Zhengzhou University, 288 Zhongzhou Middle Road, Xigong, Luoyang, Henan 471000, P.R. China

E-mail: shengxianliu721xs@163.com

Key words: vitrification embryo cryopreservation, preeclampsia, pleiotrophin, receptors

\section{Introduction}

With increasing problems of infertility $(1,2)$, the number of initiated treatments using assisted reproductive technology (ART) is rising (3). ART is a reproductive technology developed to achieve pregnancy as a fertility treatment. ART contributed to $\sim 1.6 \%$ of births in the United States in 2013 (4). At present, embryo cryopreservation is an essential technology used in ART (5), and it is important in ART as, rather than immediately transferring into the uterus, embryo cryopreservation allows supplementary embryos to be reserved for later pregnancy attempts $(6,7)$. Controlled-rate freezing and vitrification are two cryopreservation techniques that prevail in embryo cryopreservation. Although the former was the first to be applied and developed, the latter has gained increased attention due to its increasingly efficacious clinical outcomes (8). Vitrification is a cryopreservation method whereby the embryo can be cooled at ultra-fast rates (9). The main advantage of vitrification is the absence of ice crystal formation, which reduces the damage accompanying chilling. Furthermore, it does not rely on expensive programmable freezing equipment (10-12). Although the proportion of births has been increased by embryo cryopreservation due to significant improvements in technology (13), adverse perinatal outcomes have been commonly observed in pregnancies following ART, compared with those women who conceive naturally and with preeclampsia (PE) $(14,15)$. In addition, compared with fresh embryo transplantation, increased risk of PE in embryo cryopreservation has been reported (15).

As an obstetrical complication, PE is a condition that emerges after the 20th week of gestation. This disorder accounts for preterm deliveries and subsequent neonatal morbidity (16-18). PE is a primary contributor to the poor prognosis of the mother and the baby, and it is usually accompanied by the occurrence of high blood pressure, an increase in the level of urine protein and other severe organ impairments $(19,20)$. In addition, coagulant dysfunction also involved in PE (21). A previous study reported a maternal mortality rate of 50,000-60,000 caused by PE each year worldwide (22). Although extensive efforts have been made, the exact etiology of PE remains to be elucidated. It has been suggested that PE is a systemic maternal inflammatory response in which oxidative stress occurs. According to previous studies $(23,24)$, the pathogenesis of PE can be divided into two stages, namely abnormal 
placentation and endothelial dysfunction. The implantation of placenta in early pregnancy is mainly realized by the trophoblast infiltration of spiral arteries, proteolytic enzymes and the activity of adhesion molecules (24).

Multiple growth factors are involved in the progress of PE (25). As a secreted cytokine that serves as heparinbinding growth factor, pleiotrophin (PTN) is associated with various cellular events via distinct receptors (26), including inflammatory conditions (27). The expression of PTN, receptor syndecan-1 (SDC1) and receptor protein tyrosine phosphatase $\beta / \zeta(\operatorname{RPTP} \beta / \zeta)$ are found in the placenta, and are critical to the infiltration of trophoblast cells and damage of the vascular endothelium. PTN/RPTP $\beta / \zeta$ also regulates the oxidative stress response (26). As two of the receptors of $\mathrm{PTN}$, anaplastic lymphoma kinase (ALK) and syndecan-3 (SDC3) are essential to human placentation (26). However, to the best of our knowledge, the effect of PTN on and its receptors in PE in pregnancy following transplantation of embryo cryopreservation by vitrification have not been investigated or presented.

Therefore, the objective of the present study was to investigate the effect of embryo cryopreservation by vitrification in terms of the risk of PE. The effect of PTN knockout on PE in pregnancy following vitrified-warmed embryo transfer was also examined. This may reveal a biomarker for the prediction of pregnancy outcome following transplantation of embryo cryopreservation.

\section{Materials and methods}

Patient samples. The 188 patients recruited were those who received ART treatment between April, 2012 and November, 2016 at Luoyang Central Hospital Affiliated to Zhengzhou University (Luoyang, China). All protocols associated with humans in the present study were approved by the Review Board of Luoyang Central Hospital Affiliated to Zhengzhou University. All participants provided permission to cooperate to undertake the relevant study and provided written informed consent. The study included 188 cycles. The inclusion criteria were as follows: Age, 20-38 years, embryo freezing storage period between 30 and 1,080 days, vitrification was applied as an embryo cryopreservation method. Patients with a history of chronic hypertension (and/or used antihypertensive medication prior to pregnancy), multifetal gestation, or metabolic dysfunctions were excluded from the study. According to standard criteria (26), PE was defined as gestational hypertension with proteinuria.

Animals. The study was performed under the approval of the Animal Ethics Committee of Luoyang Central Hospital Affiliated to Zhengzhou University. The $\mathrm{PTN}^{-/}$mice were generated by deleting exons $2-4$ on a background of $129 /$ OlaxC57BL/6 J as described in two previous studies $(28,29)$. The animals (614 female mice, 8 -10 weeks old, weighing 18-25 g) obtained from Nanjing Biomedical Research Institute (Nanjing, China) were divided into [WT (304 mice) group and $\mathrm{PTN}^{-/}$(310 mice) group] for the preparation of false pregnancy. The animals had free access to food and water and were housed at $22^{\circ} \mathrm{C}(60-70 \%$ humidity, $12 \mathrm{~h}$ light/12 dark). The average body weight of the mice in each group was between 20 and $25 \mathrm{~g}$
(8-10 weeks of age). The genotype of $\mathrm{PTN}^{-/-}$mice was identified using a polymerase chain reaction method as previously described (30). The primers used were as follows: Forward, 5'-GATTGAACAAGATGGATTGC-3' and reverse, 5'-CAT TTAGGCAAACAGGAAGGACG-3'. The genomic DNA extracted from tails of $\mathrm{PTN}^{-/}$(a total of 310 mice) and WT mice (a total of 304 mice) was used as the template. The temperature protocols was set as: $94^{\circ} \mathrm{C}, 5 \mathrm{~min} ; 35$ cycles of $94^{\circ} \mathrm{C}, 30 \mathrm{sec}$, $63^{\circ} \mathrm{C}, 30 \mathrm{sec}, 72^{\circ} \mathrm{C} 1 \mathrm{~min}$; final extension at $72^{\circ} \mathrm{C}, 10 \mathrm{~min}$.

In vitro fertilization. An intraperitoneal injection of permanentmagnet synchronous generator (PMSG) (5 IU/mice; Ningbo Sansheng Pharmaceutical Co., Ltd., Ningbo, China) was administered to female mice ( 75 mice, 8 weeks old, weighing $18 \mathrm{~g})$. After $48 \mathrm{~h}$, human chorionic gonadotropin was then injected (5 IU/mouse; Ningbo Sansheng Pharmaceutical Co., Ltd.). The eggs were collected $14 \mathrm{~h}$ later. In brief, the female mice (weight, $18 \mathrm{~g}$ ) were sacrificed by cervical dislocation and following disinfection, the fallopian tubes were rapidly isolated and washed in PBS working buffer. The abdomen of the fallopian tube was then opened with ophthalmic forceps under a stereomicroscope. The egg granule cell complex was collected and washed in PBS and HTF medium (Quinn's; SAGE-In vitro Fertilization, Inc., Trumbull, CT, USA). The sperm from the cauda epididymis of male mice ( 25 mice, 8 weeks old) were incubated in HTF medium covered with paraffin oil (Sigma; EMD Millipore, Billerica, MA, USA) at $37^{\circ} \mathrm{C}$ for $1 \mathrm{~h}\left(5 \% \mathrm{CO}_{2}\right.$ atmosphere). Following this treatment, the sperm (final sperm concentration, $2.0 \times 10^{6} / \mathrm{ml}$ ) were co-cultured with eggs droplets (30-40/droplets) for 4-6 h for in vitro fertilization (fertilization rate, $74.36 \%$ ). The fertilized eggs in cleavage medium covered with paraffin oil (Sigma; EMD Millipore) were maintained for 36-48 $\mathrm{h}$ in order to acquire four-cell stage embryos. Blastula medium (BM; SAGE-In vitro Fertilization, Inc.) was used to culture four-cell embryos for obtaining blastocysts.

Vitrified freezing. In brief, frozen liquid containing vitrification solution (VS) solution and equilibration solution (ES) (both from Kitazato, Tokyo, Japan) were prepared $30 \mathrm{~min}$ in advance. The blastocysts were maintained in ES for $10 \mathrm{~min}$ and in VS for $30 \mathrm{sec}$. Finally, the embryos were transferred onto the top of Cryotop (Kitazato) with a minimal volume of embryo solution attached, which were immediately stored in liquid nitrogen. The contact time of the embryo with the VS liquid was between 30 and $60 \mathrm{sec}$. For thawing, the blastocysts maintained in Cryotop were collected and directly immersed in thawing solution for $60 \mathrm{sec}$, and then in diluent solution for $60 \mathrm{sec}$, in washing solution (WS) 1 for $3 \mathrm{~min}$, and in WS2 for $3 \mathrm{~min}$. The blastocysts were then transferred into BM covered with mineral oil for $1.5-2.5 \mathrm{~h}$.

Blastocyst transfer. The male mice ( 8 weeks old, weighing 20-22 g, Nanjing Biomedical Research Institute) were vascularized under the anesthesia status. The mice were anesthetized by the intravenous administration of sodium pentobarbital solution ( $2 \mathrm{mg} / \mathrm{ml}$; Solarbio, Beijing, China) (30-50 mg/ kg body weight). In brief, following anesthesia, the mice were disinfected with $70 \%$ ethanol. The vas deferens of the mice was 'picked up' with tweezers and was ligated. The vas deferens was then cut off in the middle of the two ligatures. 
The healed vasectomized male mice were mated with estrous female mice from the WT group and $\mathrm{PTN}^{-/}$group as already described. The following morning, the female mice with copulatory plugs were selected as recipients for pseudopregnancy for $12 \mathrm{~h}$. The frozen-thawed blastocysts were then transferred into the recipients at 2.5 days of pseudopregnancy.

Tax treatment. Following the blastocyst transfer, the pregnant WT and $\mathrm{PTN}^{-/}$mice were injected intraperitoneally with either corn oil taxsolution (3 mg/40 g body weight; Sigma; EMD Millipore) or an equal volume of corn oil vehicle solution on day 10 of pregnancy. The tax was injected for 5 days consecutively. This dose regimen has been reported previously (31). Four groups were established in terms of the genotype and treatment: WT corn oil (Wt) (63 mice), WT tax $(\operatorname{tax} / \mathrm{Wt})(62$ mice $), \mathrm{PTN}^{-/}$corn oil $\left(\mathrm{PTN}^{-/}\right)(64$ mice $)$ and the $\mathrm{PTN}^{-/} \operatorname{tax}\left(\operatorname{tax} / \mathrm{PTN}^{--}\right)$(64 mice). Following 19-21 days of blastocyst transfer, the next-generation mice were born. According to the occurrence PE of in mice during pregnancy, the mice in each group were further divided into PE and non-PE mice. Thus, there were 8 groups as follows: WT corn oil, PE/WT corn oil (PE/Wt), WT tax (tax/Wt), PE/WT tax $(\mathrm{PE} / \mathrm{tax} / \mathrm{Wt})$, $\mathrm{PTN}^{-/}$corn oil $\left(\mathrm{PTN}^{-/}\right), \mathrm{PTN}^{-/}$corn oil $\left(\mathrm{PE} / \mathrm{PTN}^{-/}\right)$, the $\mathrm{PTN}^{-/-}$ $\operatorname{tax}\left(\operatorname{tax} / \mathrm{PTN}^{-/}\right)$and $\mathrm{PE} / \mathrm{PTN}^{-/-} \operatorname{tax}\left(\mathrm{PE} / \operatorname{tax} / \mathrm{PTN}^{-/}\right)$.

Enzyme-linked immunosorbent assay (ELISA). The blood samples were collected via venipuncture into tubes containing anticoagulants. The protein level of PTN in serum was determined on covered 96-well ELISA plates, as previously reported (32). Rabbit anti-human PTN monoclonal antibodies (1:2,000, ab14025; Abcam, Cambridge, MA, USA) were diluted in Tris-buffered saline (TBS) and incubated at $4^{\circ} \mathrm{C}$ overnight. Biotinylated affinity-purified anti-rabbit secondary antibody (1:50,000, ab6720; Abcam) was added into the wells and incubated at room temperature for $1 \mathrm{~h}$. Streptavidin/alkaline phosphatase conjugate (Roche Diagnostics GmbH, Mannheim, Germany) was added and maintained at room temperature. The absorbance at $405 \mathrm{~nm}$ was measured on a plate reader. Recombinant human PTN (R\&D Systems, Inc.) was used as a standard control. The concentration of TNF- $\alpha$ was also measured using an ELISA kit (ab181421; Abcam) according to the protocols. The kit mainly consists of anti-TNF- $\alpha$ antibodies and the regent for the ELISA assay. The absorbance of $\mathrm{TNF}-\alpha$ was determined at $450 \mathrm{~nm}$.

Blood pressure measurement. The non-invasive tail-cuff method using the CODA ${ }^{\mathrm{TM}}$ system (Kent Scientific, Torrington, CT, USA) was applied to monitor the blood pressure of mice following the steps described in a previous study (33). The measurements were all performed 5 min prior to the start of the experiment. The assessments were repeated four times for each measurement.

Measurement of urine protein concentration. The urine was sampled using a bladder massage method, as described previously (34). The quantity of urine protein was determined using a Bradford assay (Bio-Rad Laboratories, Inc., Hercules, CA, USA). Standard solutions were diluted with Bradford regent, and the mixture of the two was incubated at room temperature for $5 \mathrm{~min}$. The absorbance was read at $595 \mathrm{~nm}$ and then a standard curve was obtained. The urine protein level was assessed according to this curve.

Immunohistochemistry (IHC) and hematoxylin and eosin (H\&E) staining. The paraffin-embedded placental and kidney tissues from the pseudopregnant mice were dewaxed and rehydrated. For H\&E staining, the sections (4- $\mu$ m-thick) were stained with hematoxylin at room temperature for $10 \mathrm{~min}$. Following incubation with $1 \%$ hydrochloric acid ethanol for $3 \mathrm{sec}$, the section was stained with $0.5 \%$ eosin for $30 \mathrm{sec}$. For IHC, the sections were preheated in distilled water at $37^{\circ} \mathrm{C}$. The sections were first heated at $120^{\circ} \mathrm{C}$ in citric acid buffer and then maintained at room temperature for $20 \mathrm{~min}$ for antigen retrieval. Fetal calf serum (Gibco/Thermo Fisher Scientific, Waltham, MA, USA) in PBS (20\%) was incubated with the sections for $10 \mathrm{~min}$. The primary antibody was added onto the sections and maintained at $4{ }^{\circ} \mathrm{C}$ overnight following removal of the serum. The secondary antibody (biotinylated) (Cell Signaling Technology, Inc.) was incubated for $30 \mathrm{~min}$. Subsequently, peroxidase-conjugated streptavidin biotin (Cell Signaling Technology, Inc.) was added and maintained for $30 \mathrm{~min}$ at room temperature. Diaminobenzidine was used to identify the peroxidase activity. Finally, the sections were counterstained with Mayer's hematoxylin (Sangon Biotech Co., Ltd., Shanghai, China). Primary antibodies used in IHC were as follows: Anti-PTN goat polyclonal (1:20, cat. no. ab223674; Abcam), anti-RPTP $\beta / \zeta$ mouse monoclonal (1:200, cat. no. sc-33664; Santa Cruz Biotechnology, Inc., Dallas, TX, USA), anti-SDC1 rabbit monoclonal (1:2,000, cat. no. ab128936; Abcam) and anti-SDC3 rabbit monoclonal (1:20, ab36653, antibody). The corresponding goat anti-rabbit IgG (ab64256, 1:200) or goat anti-mouse IgG (ab64255, 1:200) secondary antibodies used were all biotinylated and purchased from Abcam.

Western blot analysis. Lysates from the placenta were denatured in boiling water for $5 \mathrm{~min}$. The lysates ( $25 \mu \mathrm{g} /$ lane) were mixed with loading buffer and electrophoresed on a $12 \%$ SDS PAGE gel. The proteins were then transferred onto PVDF membranes. To block the non-specific proteins, not fatty milk was incubated with the membrane for $2 \mathrm{~h}$ at room temperature. Anti-pleiotrophin (1:10,000, cat. no. ab79411; Abcam), antiRPTP $\beta / \zeta ~(1: 800$, cat. no. sc33664; Santa Cruz Biotechnology, Inc.), anti-Syndecan-1 (1:1,000, cat. no. ab181789), anti-SDC3 (1:1,000, cat. no. ab155952) (both from Abcam), anti-anaplastic lymphoma kinase (ALK; cat. no. sc-398791; Santa Cruz Biotechnology, Inc.) and anti-actin antibodies (1:1,000, cat. no. ab8226; Abcam) were used as the primary antibodies. The primary antibodies were incubated with the membranes at $4^{\circ} \mathrm{C}$ overnight. The appropriate HRP-conjugated IgG secondary antibody (ab6721, 1:2,000; Abcam) was incubated with the membranes at room temperature for $1 \mathrm{~h}$. An ECL system (Amersham; GE Healthcare Life Sciences, Chalfont, UK) was used to detect the bands.

Statistical analysis. Data are shown as the means \pm standard deviation (SD) and were analyzed using a two-tailed Student's t-test or one-way analysis of variance followed by Tukey's post hoc test. $\mathrm{P}<0.05$ was considered to indicate a statistically significant difference. GraphPad Prism version 6.0 
Table I. Clinical outcomes of vitrified-warmed embryo transfer in humans.

\begin{tabular}{lc}
\hline Factor & Number \\
\hline Women & 188 \\
Embryos vitrified & 441 \\
Embryos recovered & 302 \\
Embryos transferred & 132 \\
Clinical pregnancy rate & 89 \\
Abortions & 13 \\
Stillbirth and neonatal death & 2 \\
Preeclampsia & 12 \\
\hline
\end{tabular}

Table II. Concentrations of TNF- $\alpha$ and PTN in pregnant women.

\begin{tabular}{lcc}
\hline Group & TNF- $\alpha(\mathrm{pg} / \mathrm{ml})$ & PTN $(\mathrm{ng} / \mathrm{ml})$ \\
\hline PE patients & $29 \pm 4$ & $6 \pm 13$ \\
Normal patients & $12 \pm 3$ & $8 \pm 17$ \\
P-value & $<0.05$ & 0.69 \\
\hline
\end{tabular}

TNF- $\alpha$, tumor necrosis factor- $\alpha$; PTN, pleiotrophin; PE, preeclampsia.

(GraphPad Software, Inc., La Jolla, CA, USA) was used to perform the statistical analyses.

\section{Results}

Clinical outcome results of vitrified-warmed embryo transfer. PE in pregnancies following ART has gained increased attention (35). The clinical characteristics of the patients in the present study are summarized in Table I. It was found that the incidence of PE following vitrified-warmed embryo transfer was $13.5 \%$ (12/89). PE is considered to be systematical inflammatory responses. The concentration of TNF- $\alpha$ was determined by ELISA, which is closely associated with inflammation (25). Notably, as shown in Table II, increased secretion of TNF- $\alpha$ was observed in patients with PE than that in normal pregnant women $(29 \pm 4$ vs. $12 \pm 3 \mathrm{pg} / \mathrm{ml}, \mathrm{P}<0.05)$. It was also found that the activity of PTN was reduced in patients with PE $(6 \pm 13 \mathrm{ng} / \mathrm{ml})$ when compared with the normal patients $(8 \pm 17 \mathrm{ng} / \mathrm{ml})$.

Outcome of vitrified-warmed embryo transfer in mice. To investigate the potential influence of PTN on the incidence of PE following vitrified-warmed embryo transfer, the present study evaluated the pregnancy outcome of the conditional induced PTN-deficient mice. As shown in Table III, the knockdown of PTN did not affect the pregnancy rate, which was $\sim 40 \%$ among the four groups. However, compared with the $\mathrm{PTN}^{-/-}$group $(\mathrm{P}<0.05)$, the birth rate in the tax $/ \mathrm{PTN}^{-/-}$group decreased by almost half. In addition, the incidence of PE was significantly increased by the deficiency of PTN compared with that in the $\mathrm{PTN}^{-/-}$group $(\mathrm{P}<0.05)$.
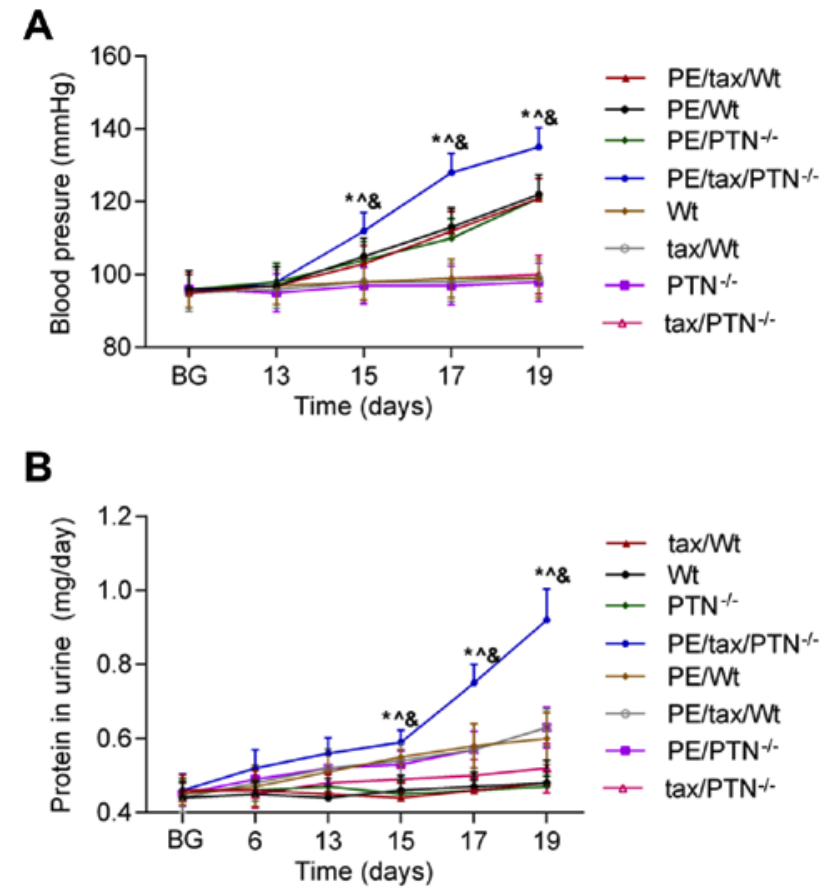

Figure 1. (A) Blood pressure at BG and at different periods following embryo transfer in mice with or without PE. (B) Urine protein levels at BG and at different periods following embryo transfer in mice with or without PE determined using a Bradford assay; ${ }^{*} \mathrm{P}<0.05$ vs. $\mathrm{PE} / \mathrm{Wt} ;{ }^{\wedge} \mathrm{P}<0.05$ vs. $\mathrm{PE} / \mathrm{tax} / \mathrm{Wt}$; ${ }^{\&} \mathrm{P}<0.05$ vs. $\mathrm{PE} / \mathrm{PTN}^{-/}$. At least eight mice were included. $\mathrm{PE}$, preeclampsia; $\mathrm{BG}$, before gestation; Wt, wild-type; tax, tamoxifen; PTN, pleiotrophin.

As increased hypertension and urine protein content are two principal features of $\mathrm{PE}$, the present study monitored the change of blood pressure and the content of urine protein in mice prior to and following their pregnancies at certain stages. These two parameters in control mice (non-PE mice) were maintained at a normal level throughout the study. As shown in Fig. 1, the blood pressure of the PE mice remained stable prior to pregnancy and in early pregnancy (during the first 13 days of pregnancy). At day 15 of pregnancy, a significant increase in blood pressure was observed in these PE mice. In addition, the blood pressure in those PE mice that lacked PTN was higher than that in the other PE mice (PE/Wt. vs. PE/tax/PTN ${ }^{-/}$at 15 days: $105 \pm 5.0$ vs. $112 \pm 4.8 \mathrm{mmHg}, \mathrm{P}<0.05$ ). Additionally, the protein content of urine in the PE mice began to increase from day 13 of pregnancy, and was higher in the PE mice that lacked PTN than in the other mice with $\mathrm{PE}$ (Wt vs. tax $/ \mathrm{PTN}^{-/}$at 13 days: $0.51 \pm 0.05$ vs. $0.565 \pm 0.038 \mathrm{mg} / \mathrm{day}, \mathrm{P}<0.05)$. From day 19 of pregnancy, the blood pressure and the urine protein content reached the highest levels in the PE mice that lacked PTN.

Concentrations of TNF- $\alpha$ and PTN in mice. To determine the effect of PTN on PE following vitrified-warmed embryo transfer, the activities of PTN and TNF- $\alpha$ were identified in mice. As shown in Fig. 2A, the release of PTN was reduced in the PE mice as pregnancy progressed, and the release of PTN was higher in the PE mice that lacked PTN than in the other mice with PE. The secretion of TNF- $\alpha$ showed an increasing trend in the PE mice as pregnancy progressed. The level of PTN was low in the PE mice that lacked PTN compared with the other mice with PE, and the content of TNF- $\alpha$ was highest in the PE mice that lacked PTN (Fig. 2B). 
Table III. Outcomes of vitrified-warmed embryo transfer in mice.

\begin{tabular}{lcccc}
\hline Factor & Wt & tax/Wt & PTN $^{-/-}$ & tax/PTN $^{-/-}$ \\
\hline Animals (n) & 152 & 152 & 156 & 155 \\
Transferred embryos (n) & 694 & 695 & 706 & 703 \\
Pregnancy rate, n (\%) & $63(41.4)$ & $62(40.7)$ & $64(41)$ & $64(41)$ \\
Total births, n (\%) & $211(30.5)$ & $210(30.2)$ & $215(30.4)$ & $123(17.5)^{\mathrm{a}}$ \\
PE (\%) & $9(14.3)$ & $9(14.5)$ & $10(14.7)$ & $24(37.5)^{\mathrm{a}}$ \\
\hline
\end{tabular}

${ }^{\mathrm{a}} \mathrm{P}<0.05$, compared with $\mathrm{PTN}^{-/}$. PE, preeclampsia; Wt, wild-type; tax, tamoxifen; PTN, pleiotrophin.
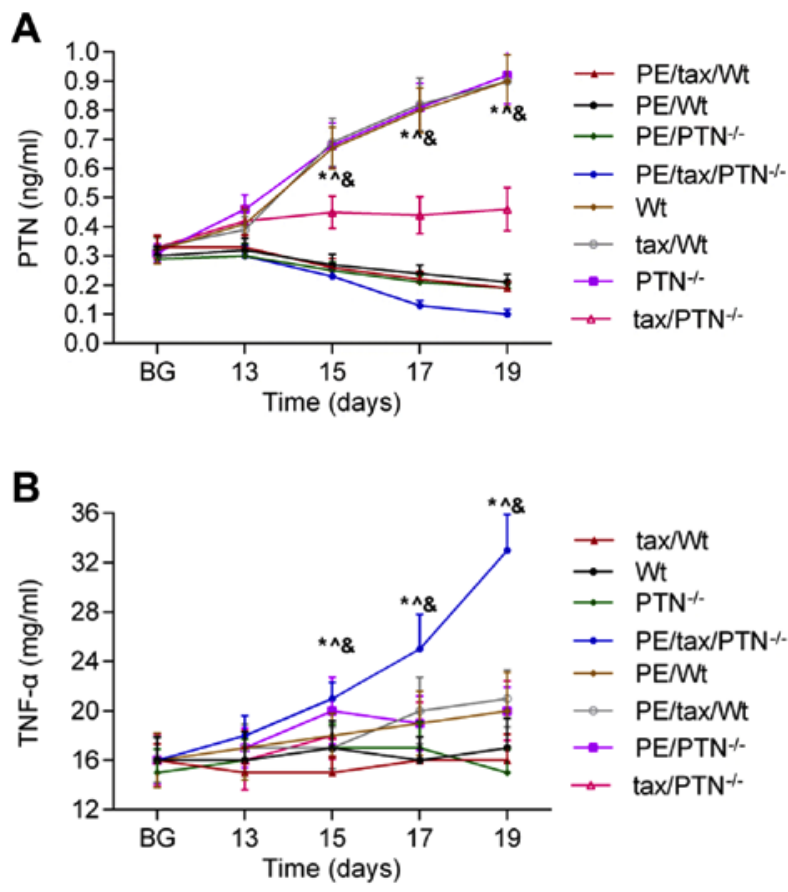

Figure 2. (A) Levels of PTN prior to gestation and at different periods following embryo transfer, determined using an ELISA in PE mice. (B) Levels of TNF in mice prior to gestation and at different periods following embryo transfer, determined by ELISA in PE mice. ${ }^{*} \mathrm{P}<0.05$ vs. $\mathrm{PE} / \mathrm{Wt}$; ${ }^{\wedge} \mathrm{P}<0.05$ vs. $\mathrm{PE} / \mathrm{tax} / \mathrm{Wt} ;{ }^{\&} \mathrm{P}<0.05$ vs. $\mathrm{PE} / \mathrm{PTN}{ }^{-1}$. $\mathrm{PE}$, preeclampsia; BG, before gestation; Wt, wild-type; tax, tamoxifen; PTN, pleiotrophin; TNF- $\alpha$, tumor necrosis factor- $\alpha$; ELISA, enzyme-linked immunosorbent assay.

Expression of PTN and its receptors in placental tissue. PTN is involved in inflammation via its distinct receptors (36). The present study compared the expression level of PTN and its receptors in the placenta of PE and normal mice. As shown in Fig. 3, the expression levels of PTN, $\mathrm{SDC} 1, \mathrm{SDC} 3$ and $\mathrm{RPTP} \beta / \zeta$ were reduced in the PE mice when compared with levels in the normal mice, whereas the expression level of ALK was similar among the groups. It appears that the expression levels of SDC1 and SDC3 were not affected significantly by the knockdown of PTN, whereas the expression of RPTP $\beta / \zeta$ appeared to be suppressed by the knockdown of PTN. In order to determine whether PTN and its receptors are involved in PE following vitrified-warmed embryo transfer, the expression pattern of PTN and its receptors in each group were determined by IHC $(n=4)$. Staining for the expression of PTN was present in the cytoplasm and mesenchyme (ME) in the placenta of control mice, whereas perinuclear and ME staining was weaker in the placenta of $\mathrm{PE}$ mice (Fig. 4). The PTN staining faded out in mice that lacked PTN, although PTN staining remained present in the tax/ $\mathrm{PTN}^{-/}$mice as the efficiency of the conditional knockout was not $100 \%$ effective (negative staining for the isotype control of PTN; data not shown). The expression of PTN was almost absent in the $\operatorname{tax} / \mathrm{PTN}^{-/} \mathrm{PE}$ mice (Fig. 4D). In the placental tissues of the control mice, strong fetal macrophage (FM) staining for SDC1 was also observed. Fainter staining was observed in the ME and fetal vessels (FV). In the PE mice, not all FMs were stained and other staining had almost disappeared (Fig. 5). The expression ofSDC1 appeared to be reduced in the PTN-knockout mice (Fig. 5D). Strong diffuse cytoplasmic staining for RPTP $\beta / \zeta$ was also noted. Intensive staining in the ME, villous cytotrophoblasts, syncytiotrophoblasts and FMs were observed in the control mice. However, this staining was weaker or absent in the placenta of the PE mice (Fig. 6).

Kidney injury in mice. Renal damage is often connected to PE (37). Therefore, the present study examined kidney injury in the mice. As shown in Fig. 7, the glomeruli, renal capsule and tubular structures were clear in the kidneys of the control mice. However, the Bowman's capsule and the opening of capillary loops were reduced, and inflammatory cell infiltration increased in the PE mice. In addition, kidney injury was more severe in the PTN-knockout PE mice.

\section{Discussion}

The risk of PE in pregnancies following ART is high (38). $\mathrm{PE}$ is a maternal complication accompanied with high blood pressure and an increase of urine protein during pregnancy. The incidence of PE is $5-8 \%$ worldwide $(39,40)$. The present study analyzed the outcome of clinical pregnancy following embryo transfer. The results showed that the incidence of PE was higher (12\%) in mice conceiving through vitrified-thawed embryo transfer. Therefore, it is of medical importance to further investigate the molecular mechanism of PE.

$\mathrm{PE}$ is considered to be a type of systemic inflammatory responses. Poor placentation and endothelial disorder are two critical stages of PE (24). Heparin-binding growth factors, including PTN, have been reported to be altered in PE. PTN is distributed in the placenta and is important to placentation and inflammation via its receptors. The results of the present study showed that the concentrations of TNF- $\alpha$ and 

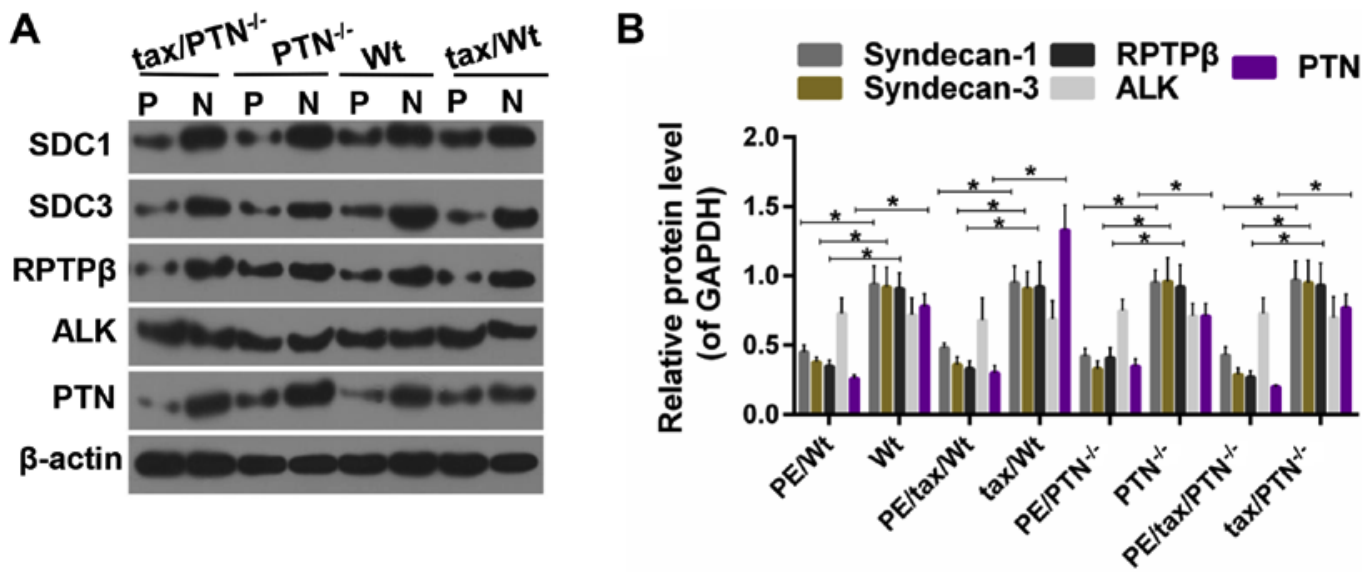

Figure 3. Expression of PTN and its receptors. (A) Western blots for the expression level of PTN and its receptors. (B) Determination of the protein level of PTN and its receptors. "P $<0.05$. The experiments were repeated at least three times independently. PE, preeclampsia; Wt, wild-type; tax, tamoxifen; PTN, pleiotrophin; SDC1,syndecan-1; SDC3,syndecan-3; RPTP $\beta$, receptor protein tyrosine phosphatase $\beta / \zeta$; ALK, anaplastic lymphoma kinase; P, PE; N, normal.

A

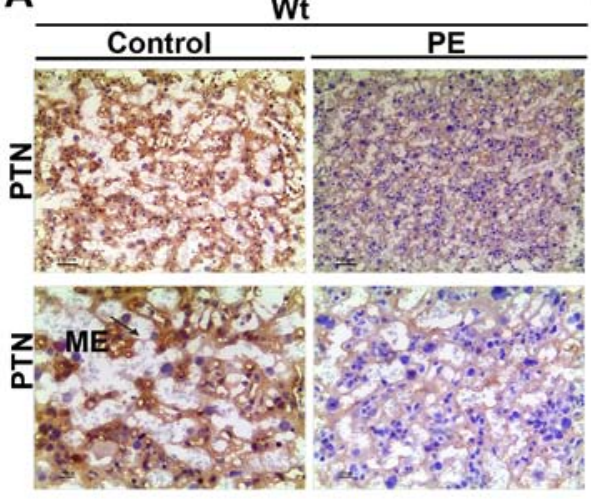

C

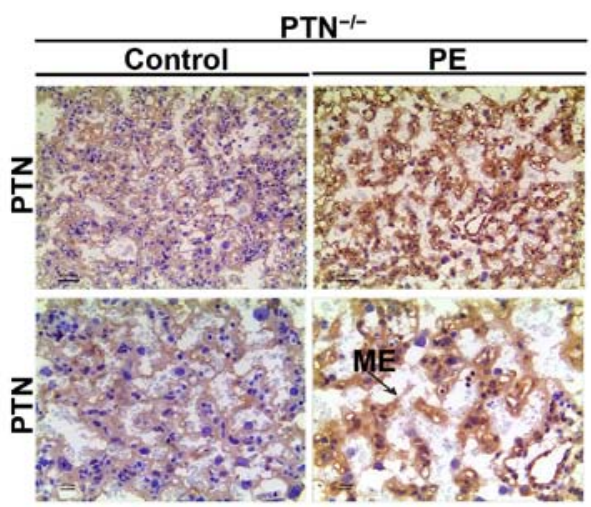

B

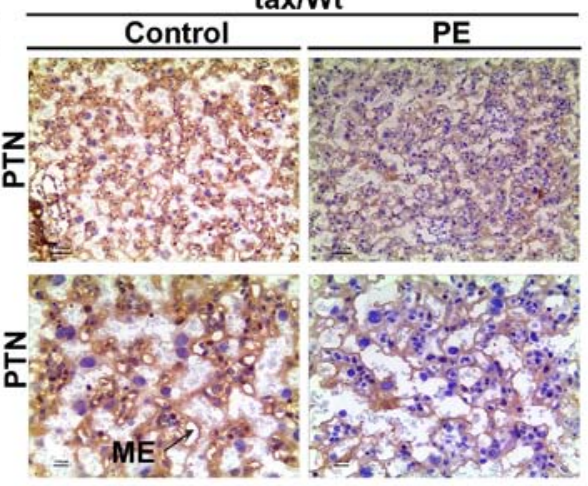

D

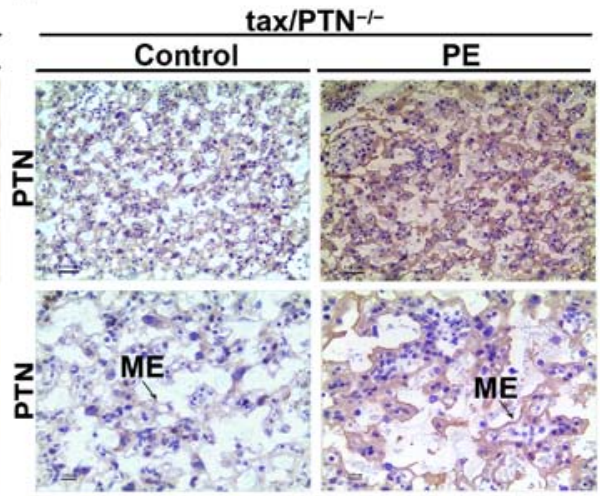

Figure 4. Immunohistochemistry for the expression pattern of PTN in the placenta. Expression of PTN in the (A) Wt group, (B) tax/Wt group, (C) PTN ${ }^{-/}$ group, and (D) tax $/ \mathrm{PTN}^{-/}$group; arrows indicate the ME. The experiments were repeated at least three times independently. PE, preeclampsia; Wt, wild-type; tax, tamoxifen; PTN, pleiotrophin; ME, mesenchyme. Magnification, x100 for the upper row and x 200 for the lower row.

PTN were increased and decreased, in pregnant women with PE, compared with those in non-PE women, respectively. The enhanced secretion of TNF- $\alpha$ was in accordance with a previous study (41). In addition, to a certain extent, the decreased PTN suggested its potential role in PE. However, less is known regarding the role of PTN on the incidence of PE following embryo transfer. Therefore, the present study focused on whether and how PTN knockout affects the risk of PE following vitrified-thawed embryo transfer.
Compared with the wild-type group, the present study found that the risk of $\mathrm{PE}$ in $\mathrm{PTN}^{-/}$mice was increased following treatment with tax. In addition, the blood pressure and urine protein content were increased in PE mice as time progressed, and these reached the highest levels on day 19 of pregnancy. Furthermore, the blood pressure and urine protein content were higher in the PE mice treated with tax than that in the other PE mice. In addition, the level of PTN increased as pregnancy progressed in the non-PE mice, but declined in 
A

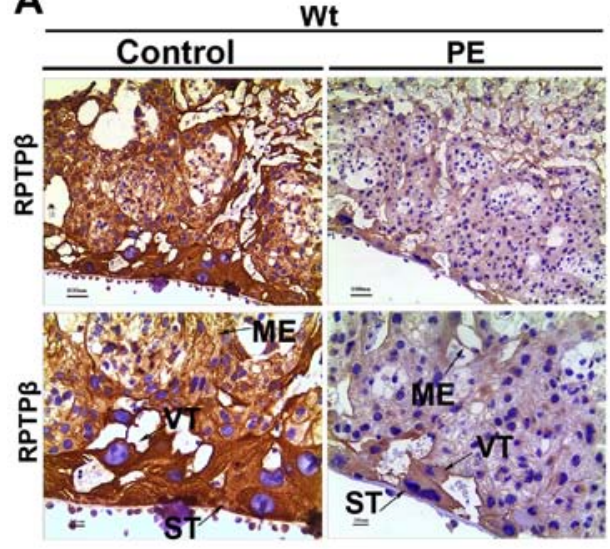

C

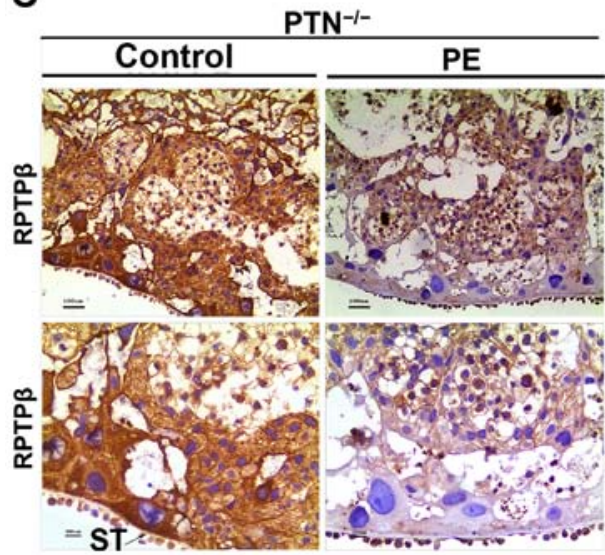

B

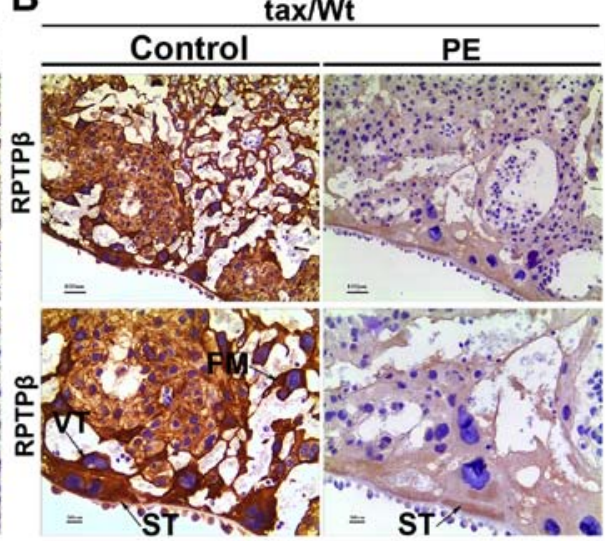

D

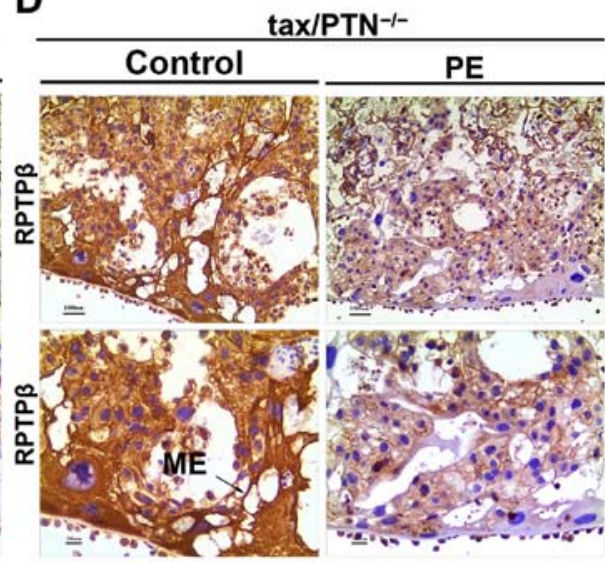

Figure 5. Immunohistochemistry for the expression pattern of RPTP $\beta / \zeta$ in the placenta of the (A) Wt group (arrows indicate ME, VT and ST), (B) tax/Wt group (arrows indicate FM, VT and ST), (C) PTN ${ }^{-/}$group (arrows indicate ST), and (D) tax/PTN $\mathrm{P}^{-/}$group (arrows indicate the ME). The experiments were repeated at least three times independently. PE, preeclampsia; Wt, wild-type; tax, tamoxifen; PTN, pleiotrophin; RPTP $\beta / \zeta$, receptor protein tyrosine phosphatase $\beta / \zeta$; ME, mesenchyme; VT, villous cytotrophoblast; ST, syncytiotrophoblast; FM, fetal macrophage. Magnification, x100 for the upper row and x200 for the lower row.

the PE mice. By contrast, the level of TNF- $\alpha$ remained at a steady level in the non-PE mice, but increased in the PE mice as pregnancy progressed. Similar to blood pressure and urine protein content, the activity of TNF- $\alpha$ was higher in the PE mice treated with tax than that in the other PE mice. These results indicated that the reduction of PTN increased the risk of PE following vitrified-thawed embryo transfer.

The function of PTN is largely dependent on its receptors (42). To further examine the role of PTN in the occurrence of PE, western blot analysis was performed to determine the expression of PTN and its receptors, including SDC1, SDC3, RPTP $\beta / \zeta$ and ALK, in the placenta. The data showed that the expression of $\mathrm{RPTP} \beta / \zeta$ was reduced in PE mice treated with tax, compared with that in mice treated with corn oil, and that the expression levels of SDC1 and SDC3 were marginally suppressed in the PE mice treated with tax. As a low expression of SDC1 has been demonstrated to promote PE (43), IHC was used to identify the expression pattern of PTN, RPTP $\beta / \zeta$ and SDC1 in the placenta. The results showed that the staining for PTN was perinuclear, and was also observed in FMs and ME, which was in line with a previous study (26). These results confirmed the pro-angiogenic effect of PTN in these sites (44). The receptors SDC1 and RPTP $\beta / \zeta$ shared certain overlapping expression patterns as PTN. These results were partly in line with a previous study (26). In the present study, the finding that the staining of
PTN in the syncytial microvillous membrane was adjacent to areas of completely unstained membrane was recorded, and this suggested its variation in the membrane (45). However, the expression of PTN and its receptors was weaker in the PE mice. Notably, the expression levels of SDC1 and RPTP $\beta / \zeta$ were reduced in $\mathrm{PE}$ conditions, with no changes in $\mathrm{PE}$ mice with or without tax treatment. Although this result was not in accordance with the results from the western blot analysis, the possibility that the receptors of PTN may be associated with the incidence of PE following embryo transfer cannot be excluded. Further investigations are required to examine the role of its receptors in more detail. In addition, the present study observed that the kidney injury caused by PE was increased by the knockout of PTN. Therefore, these results indicated that the reduced activity of PTN was associated with PE following embryo transfer.

To the best of our knowledge, the present study provides the first comprehensive investigation of the potential role of PTN in PE following vitrified-thawed embryo transfer. However, the underlying mechanisms remain to be fully elucidated. The results showed that PTN may be relevant to the inflammatory response in PE, however, as a heparin-binding factor, PTN may affect the balance of the clotting/anticoagulant system via heparin, affecting the homeostasis of the clotting/anticoagulant in PE. In addition, PTN and its receptor have been reported to be involved in the metabolism of catecholamines, 
A

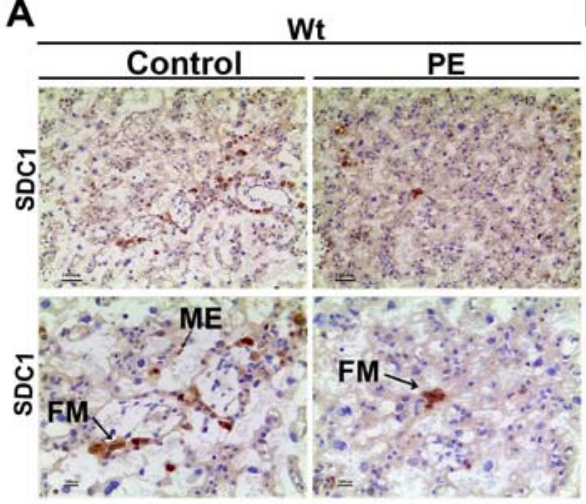

B

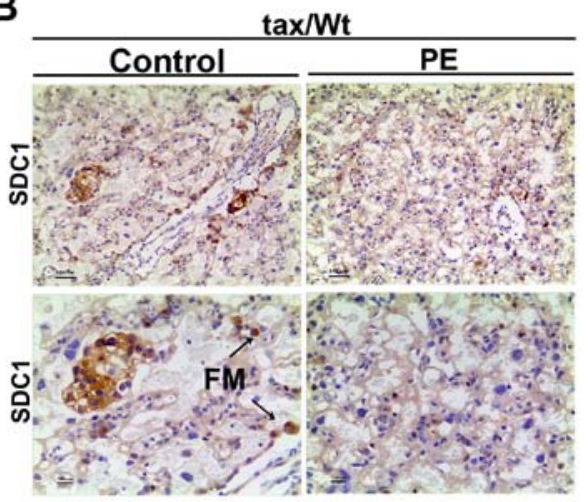

C

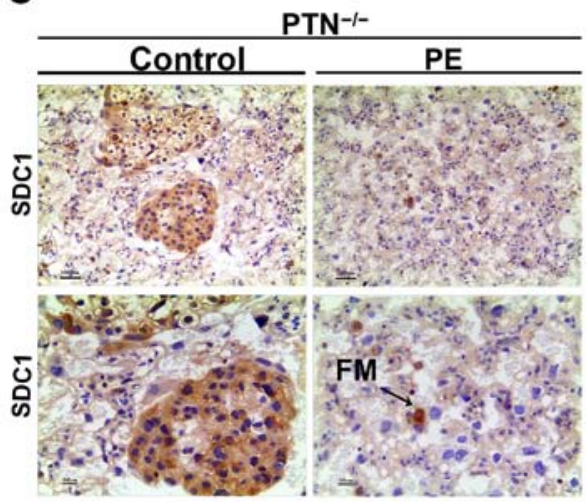

D

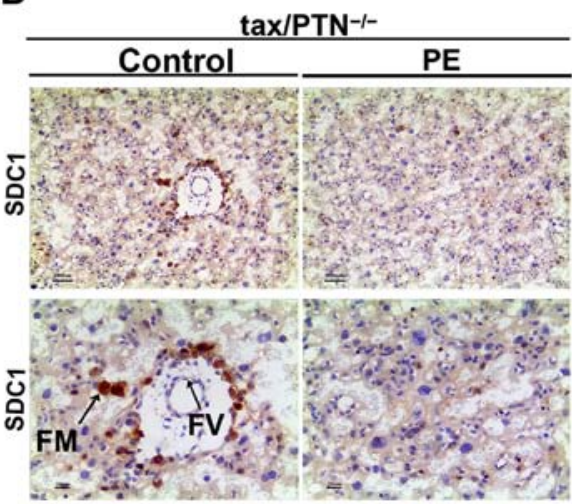

Figure 6. Immunohistochemistry for the expression pattern of SDC1 in the placenta. Expression of SDC1 in the (A) Wt group (arrows indicate FM and ME), (B) tax/Wt group (arrows indicate FM), (C) $\mathrm{PTN}^{-/}$group (arrows indicate FM), and (D) tax/PTN ${ }^{-/}$group (arrows indicate FM and FV). The experiments were repeated at least three times independently. PE, preeclampsia; Wt, wild-type; tax, tamoxifen; PTN, pleiotrophin;SDC1, syndecan-1; ME, mesenchyme, FM, fetal macrophage; FV, fetal vessel. Magnification, x100 for the upper row and x 200 for the lower row.

A

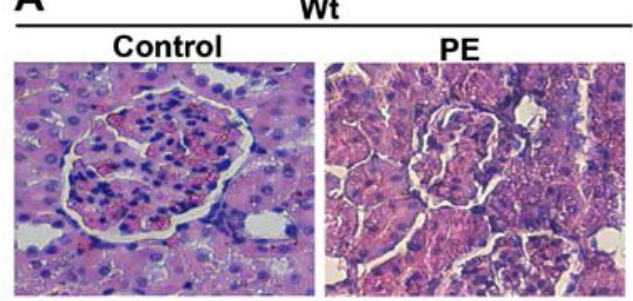

C

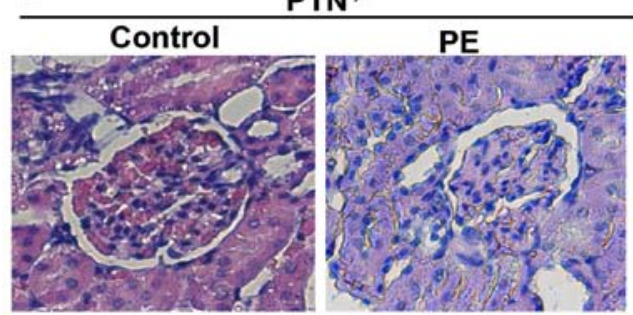

B

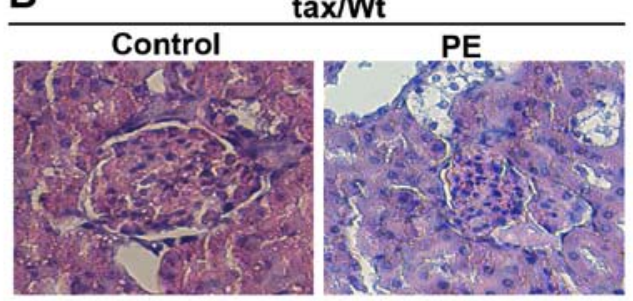

D

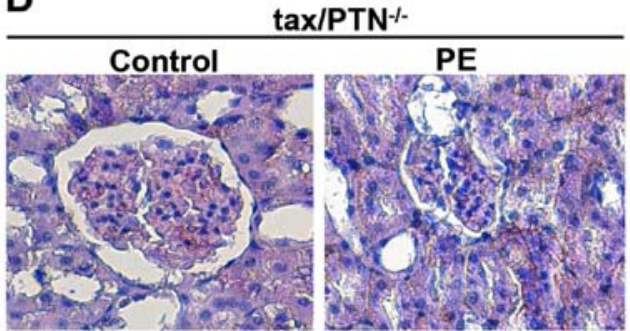

Figure 7. Hematoxylin and eosin staining of kidney tissues. (A) Wt group, (B) tax)/Wt group, (C) PTN ${ }^{-/-}$group, (D) tax/PTN ${ }^{-/-}$group. The experiments were repeated at least three times independently. PE, preeclampsia; Wt, wild-type; tax, tamoxifen; PTN, pleiotrophin. Magnification, $\mathrm{x} 200$.

and thereby regulate oxidative stress in PE $(26,46)$. Therefore, further investigation of the role of PTN and its receptors on PE following ART are required.

In conclusion, the risk of PE was shown to increase following vitrified-thawed embryo transfer; the knockout of PTN enhanced the incidence and symptoms of PE in pregnant mice following embryo transfer. In addition, the inflammatory response was more marked in PE mice that lacked PTN than that in other PE mice. The expression of PTN and its receptors reflected their possible role in PE. The present study suggested a potential direction for the detailed investigation of PTN in $\mathrm{PE}$ following embryo transfer. 


\section{Acknowledgements}

Not applicable.

\section{Funding}

This study was supported by the Henan Provincial Science and Technology Project (grant no. 201602359).

\section{Availability of data and materials}

All data generated or analyzed during this study are included in this published article.

\section{Authors' contributions}

SL wrote the main manuscript and analyzed the data. FW performed the experiments. GL conceived and designed the study. All authors have read and approved the final manuscript.

\section{Ethics approval and consent to participate}

All protocols associated with humans in the present study were approved by the Review Board of Luoyang Central Hospital Affiliated to Zhengzhou University. All participants provided permission to cooperate to undertake the relevant study and provided written informed consent. Animal experiments were performedwith the approval of the Animal Ethics Committee of Luoyang Central Hospital Affiliated to Zhengzhou University.

\section{Patient consent for publication}

Not applicable.

\section{Competing interests}

The authors declare that they have no competing interests.

\section{References}

1. Sharma A, Singh AK and Singh SK: Increasing prevalence of male infertility and stress factors: An overview. Int J Clin Cases Invest 3: 17-24, 2011.

2. Araoye MO: Epidemiology of infertility: Social problems of the infertile couples. West Afr J Med 22: 190-196, 2003.

3. Kol S: Assisted Reproductive Technology (ART). In: Encyclopedia of Endocrine Diseases. Academic Press, New York, NY, pp269-277, 2004.

4. Sunderam S, Kissin DM, Crawford SB, Folger SG, Jamieson DJ, Warner L and Barfield WD: Assisted Reproductive Technology Surveillance - United States, 2013. MMWR Surveill Summ 64 $1-25,2015$.

5. Saragusty $\mathbf{J}$ and Arav A: Current progress in oocyte and embryo cryopreservation by slow freezing and vitrification. Reproduction 141: 1-19,2011.

6. Veeck LL: Does the developmental stage at freeze impact on clinical results post-thaw? Reprod Biomed Online 6: 367-374, 2003

7. Anderson AR, Wilkinson SS, Price S and Crain JL: Reduction of high order multiples in frozen embryo transfers. Reprod Biomed Online 10: 402-405, 2005.

8. Desai N, Blackmon H, Szeptycki J and Goldfarb J: Cryoloop vitrification of human day 3 cleavage-stage embryos: Postvitrification development, pregnancy outcomes and live births. Reprod Biomed Online 14: 208-213, 2007.

9. Vajta G and Nagy ZP: Are programmable freezers still needed in the embryo laboratory? Review on vitrification. Reprod Biomed Online 12: 779-796, 2006.
10. Kuleshova LL and Lopata A: Vitrification can be more favorable than slow cooling. Fertil Steril 78: 449-454, 2002.

11. Liebermann J and Tucker MJ: Effect of carrier system on the yield of human oocytes and embryos as assessed by survival and developmental potential after vitrification. Reproduction 124 : 483-489, 2002

12. Vajta G and Kuwayama M: Improving cryopreservation systems. Theriogenology 65: 236-244, 2006.

13. Doody KJ: Cryopreservation and delayed embryo transfer-assisted reproductive technology registry and reporting implications. Fertil Steril 102: 27-31, 2014.

14. Pastore LM and Williams CD: Perinatal outcomes in singletons following in vitro fertilization: A meta-analysis. Obstet Gynecol 104: 412, 2004

15. Opdahl S, Henningsen AA, Tiitinen A, Bergh C, Pinborg A, Romundstad PR, Wennerholm UB, Gissler M, Skjærven R and Romundstad LB: Risk of hypertensive disorders in pregnancies following assisted reproductive technology: A cohort study from the CoNARTaS group. Hum Reprod 30: 1724-1731, 2015.

16. Roberts JM: Preeclampsia: New approaches but the same old problems. Am J Obstet Gynecol 199: 443-444, 2008.

17. Roberts JM, Pearson GD, Cutler JA and Lindheimer MD; National Heart Lung and Blood Institute: Summary of the NHLBI Working Group on Research on Hypertension During Pregnancy. Hypertens Pregnancy 22: 109-127, 2003.

18. Myklestad K, Vatten LJ, Salvesen KA, Davey Smith G and Romundstad PR: Hypertensive disorders in pregnancy and paternal cardiovascular risk: A population-based study. Ann Epidemiol 21: 407-412, 2011.

19. Redman CW and Sargent IL: Latest advances in understanding preeclampsia. Science 308: 1592-1594, 2005.

20. Sircar M, Thadhani R and Karumanchi SA: Pathogenesis of preeclampsia. Curr Opin Nephrol Hypertens 24: 131-138, 2015.

21. Zhang Y, Hua Z, Zhang K, Meng K and Hu Y: Therapeutic effects of anticoagulant agents on preeclampsia in a murine model induced by phosphatidylserine/phosphatidylcholine microvesicles. Placenta 30: 1065-1070, 2009.

22. American College of Obstetricians and Gynecologists; Task Force on Hypertension in Pregnancy: Hypertension in pregnancy. Report of the American College of Obstetricians and Gynecologists' Task Force on Hypertension in Pregnancy. Obstet Gynecol 122: 1122-1131, 2013.

23. Redman CW and Sargent IL: Placental stress and pre-eclampsia: a revised view. Placenta 30 (Suppl A): S38-S42, 2009.

24. Mohaupt M: Molecular aspects of preeclampsia. Mol Aspects Med 28: 169-191, 2007.

25. Das UN: Cytokines, angiogenic, and antiangiogenic factors and bioactive lipids in preeclampsia. Nutrition 31: 1083-1095, 2015.

26. Ball M, Carmody M, Wynne F, Dockery P, Aigner A, Cameron I, Higgins J, Smith SD, Aplin JD and Moore T: Expression of pleiotrophin and its receptors in human placenta suggests roles in trophoblast life cycle and angiogenesis. Placenta 30: 649-653, 2009.

27. Achour A, M'bika JP, Baudouin F, Caruelle D and Courty J: Pleiotrophin induces expression of inflammatory cytokines in peripheral blood mononuclear cells. Biochimie 90: 1791-1795, 2008.

28. Amet LE, Lauri SE, Hienola A, Croll SD, Lu Y, Levorse JM, Prabhakaran B, Taira T, Rauvala H and Vogt TF: Enhanced hippocampal long-term potentiation in mice lacking heparinbinding growth-associated molecule. Mol Cell Neurosci 17 1014-1024, 2001.

29. del Olmo N, Gramage E, Alguacil LF, Pérez-Pinera P, Deuel TF and Herradón G: Pleiotrophin inhibits hippocampal long-term potentiation: A role of pleiotrophin in learning and memory. Growth Factors 27: 189-194, 2009.

30. Gramage E, Herradón G, Martín YB, Vicente-Rodríguez M, Rojo L, Gnekow H, Barbero A and Pérez-García C: Differential phosphoproteome of the striatum from pleiotrophin knockout and midkine knockout mice treated with amphetamine: Correlations with amphetamine-induced neurotoxicity. Toxicology 306 147-156, 2013.

31. Hayashi S and McMahon AP: Efficient recombination in diverse tissues by a tamoxifen-inducible form of Cre: A tool for temporally regulated gene activation/inactivation in the mouse. Dev Biol 244: 305-318, 2002.

32. Aigner A, Brachmann P, Beyer J, Jäger R, Raulais D, Vigny M, Neubauer A, Heidenreich A, Weinknecht S, Czubayko F, et al: Marked increase of the growth factors pleiotrophin and fibroblast growth factor- 2 in serum of testicular cancer patients. Ann Oncol 14: 1525-1529, 2003 
33. Krege JH, Hodgin JB, Hagaman JR and Smithies O: A noninvasive computerized tail-cuff system for measuring blood pressure in mice. Hypertension 25: 1111-1115, 1995.

34. Monahan E and Yamazaki K: An improved urine collection technique for laboratory mice: The bladder massage method. Lab Animal 22: 38-39, 1993.

35. Martin AS, Monsour M, Kawwass JF, Boulet SL, Kissin DM and Jamieson DJ: Risk of preeclampsia in pregnancies after assisted reproductive technology and ovarian stimulation. Matern Child Health J 20: 2050-2056, 2016.

36. Kadomatsu K: The midkine family in cancer, inflammation and neural development. Nagoya J Med Sci 67: 71-82, 2005.

37. Wester-Rosenlöf L, Casslén V, Axelsson J, Edström-Hägerwall A, Gram M, Holmqvist M, Johansson ME, Larsson I, Ley D, Marsal K, et al: A1M/ 1 -microglobulin protects from hemeinduced placental and renal damage in a pregnant sheep model of preeclampsia. PLoS One 9: e86353, 2014.

38. Wang YA, Chughtai AA, Farquhar CM, Pollock W, Lui K and Sullivan EA: Increased incidence of gestational hypertension and preeclampsia after assisted reproductive technology treatment Fertil Steril 105: 920-926.e2, 2016.

39. Högberg U: The World Health Report 2005: 'Make every mother and child count' - including Africans. Scand J Public Health 33 409-411, 2005

40. Al-Jameil N, Aziz Khan F, Fareed Khan M and Tabassum H: A brief overview of preeclampsia. J Clin Med Res 6: 1-7, 2014.
41. Shaw J, Tang Z, Schneider H, Saljé K, Hansson SR and Guller S: Inflammatory processes are specifically enhanced in endothelial cells by placental-derived TNF- $\alpha$ : Implications in preeclampsia(PE). Placenta 43: 1-8, 2016.

42. Xu C, Zhu S, Wu M, Han W and Yu Y: Functional receptors and intracellular signal pathways of midkine (MK) and pleiotrophin (PTN). Biol Pharm Bull 37: 511-520, 2014.

43. Gandley RE, Althouse A, Jeyabalan A, Bregand-White JM McGonigal S, Myerski AC, Gallaher M, Powers RW and Hubel CA: Low soluble syndecan-1 precedes preeclampsia. PLoS One 11: e0157608, 2016.

44. Palmieri D, Mura M, Mambrini S and Palombo D: Effects of Pleiotrophin on endothelial and inflammatory cells: Pro-angiogenic and anti-inflammatory properties and potential role for vascular bio-prosthesis endothelialization. Adv Med Sci 60: 287-293, 2015.

45. Anjum N, Baker PN, Robinson NJ and Aplin JD: Maternal celiac disease autoantibodies bind directly to syncytiotrophoblast and inhibit placental tissue transglutaminase activity. Reprod Biol Endocrinol 7: 16, 2009.

46. Hung JH: Oxidative stress and antioxidants in preeclampsia. J Chin Med Assoc 70: 430-432, 2007. International (CC BY-NC-ND 4.0) License. 